\title{
DE METRÓPOLIS A AVATAR: O PÓS-HUMANO ANTECIPADO NO CINEMA
}

\author{
Clándio C. Paiva \\ Universidade Federal da Paraíba
}

\section{Resumo}

A realidade virtual, proclamada com o advento dos computadores e da internet, há muito tem sido focalizada no universo ficcional da literatura e do cinema, desde obras como Metropolis (1927) e 2001: uma odisséia no espaço (2001: A space odyssey, 1968), passando por Blade Runner (1982) e O exterminador do futuro (Terminator, 1984) até Matrix (1999). São filmes implacáveis em sua imaginação do futuro e radicais em sua mirada na condição do pós-humano, isto é, a conexão do Ser e da máquina numa simbiose radical. Contemplando a ficção científica do cinema (sci-fi), já disseminada na televisão e na internet, percebemos que as suas imagens e sons contêm o DNA da cibercultura, uma visão do futuro que se tornou presente no "breve século XX".

Palavras-chave: cinema, ficção, cibercultura, realidade virtual.

\section{Abstract}

Virtual reality, proclaimed with the advent of computers and the internet, has long been focused on the fictional universe of literature and film, since works such as Metropolis (1927) and 2001: A space odyssey, 1968, Blade Runner (1982) and Terminator, 1984 to the Matrix (1999) Its relentless in their vision of future and radical imagination in his look in the post-human condition, that is, the connection of the machine and in a radical symbiosis. Contemplating the film science fiction (sci-fi), already widespread on television and on the internet, we realize that your images and sounds contain the DNA of cyberculture, a vision of the future that became present in the "short 20TH century". Keywords: cinema, fiction, cyberculture, virtual reality.

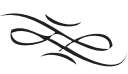


Do filme expressionista ao cinema em 3D, a realidade virtual - proclamada com o advento dos computadores, internet, games e tecnologia - tem sido projetada no universo ficcional da literatura e do cinema, desde obras como Metrópolis (1927), 2001 uma odisséia no espaço (1968), Blade Runner (1982), O exterminador do futuro (1984) até Matrix (1999) Inteligência Artificial (2001) e Avatar (2010). São obras ácidas, implacáveis em seu registro do mundo real e na imaginação do futuro, e fulminantes, em sua mirada na condição do pós-humano. As narrativas de ficção previram o ciborgue, o híbrido, o ser e a máquina numa simbiose radical, que envolve e assombra.

Contemplando a ficção científica (sci-fi), hoje em circulação na televisão e na internet, observamos que as suas imagens e sons contêm uma espécie de DNA da cibercultura; uma visão do futuro, inscrita no passado e que se tornou presente no século 21. A sétima arte antecipou uma modernidade tecnológica que simultaneamente causa medo e fascínio. E cabe aos filósofos, especialistas estetas, críticos, pedagogos, jornalistas decifrar o sentido dessas narrativas audiovisuais, históricas e ficcionais, que têm alimentado ideologias e utopias há mais de um século.

Trata-se de um repertório que - incessantemente - têm forjado um universo paralelo, cuja irradiação atravessa inteiramente a realidade sensível. O desafio que se coloca é decifrar o significado dessa modernidade tecnológica, antecipada na literatura, no cinema de ficção e realizada, em grande parte, no atual cenário da vida cotidiana.

Embora hoje encontremos ficção científica em histórias em quadrinhos, videogames, filmes e RPG, o gênero nasceu como narrativa literária. A ficção científica herdou das narrativas de viagens e das fábulas a tarefa de contar histórias sobre seres maravilhosos ou extraordinários, fascinando assim seus leitores. As viagens fantásticas, como As viagens de Gulliver, de Jonathan Swift, descrevem seres maravilhosos e lugares exóticos e longínquos, acendendo a curiosidade sobre o desconhecido, mas mantendo em suspense a real existência dos ambientes descritos. A ficção fantástica - a ficção científica e seus primos mais próximos, a fantasia e o horror - são produtos da Idade Moderna, e, constituíram-se no campo da literatura. Diferente da fábula, a literatura é ficcional, mas se compromete a produzir efeitos de realidade. A literatura fantástica permanece, no entanto, com o mesmo objetivo da fábula: criar seres e mundos desconhecidos, despertando curiosidade e deslumbramento em seus leitores.

OLIVEIRA, 2004, on line.

Para a elaboração deste trabalho, fizemos um mapeamento seletivo de algumas obras de ficção no cinema, incluindo a ficção científica, muitas delas adaptadas das narrativas literárias. São películas que apresentam um projeto estético e ideológico acerca da vida no futuro, simulando um mundo no qual convivem os seres humanos e as má- 
quinas, numa ambiência onde o natural se confunde com o artificial, o orgânico com o tecnológico, o real com o virtual.

Esses filmes, cuja ficcionalidade não cessa de se realizar no plano da vida vivida, contêm as chaves para um entendimento das relações entre os humanos e seus duplos, clones, extensões e alteridades. As artes da literatura e do cinema têm fornecido as pistas para uma imaginação filosófica do seres humanos e as suas relações com as formas de vida artificial, do "universo paralelo", comum na era das mídias digitais e previsto nas origens da ficção cinematográfica.

Desde um filme ainda tecnicamente rudimentar como Viagem à lua (1902) até o recente Aeon Flux (2005), informado pela estética dos quadrinhos, desenhos e animações, há obras fundadoras de um campo de visibilidade que traduz o nosso meio ambiente inteiramente irradiado pelas tecnologias.

As obras apontadas aqui, em diferentes registros, têm valor de culto porque são ícones importantes no imaginário ocidental, têm valor afetivo, pois são imagens obsedantes, imagens amadas e têm também valor de troca, uma vez que arrecadam milhões nas bilheterias mundiais. O cinema de ficção tem o poder de entreter, alertar e instigar, face à hiper-realidade cotidiana forjada pelas tecnologias. A ficcionalidade do cinema reafirma estilos de identidade e de identificação dos indivíduos, espectadores, cidadãos imersos na cultura das redes midiáticas. O cinema é, sobretudo, um possante vetor de inteligência e sensorialidade que gera vigorosas modalidades de percepção, cognição e contemplação do mundo.

\begin{abstract}
A obra de ficção científica, ao projetar futuros, fala do presente para entender passados e, assim, aponta alternativas para futuros já irrealizáveis. Por isso, a impossível tristeza desses futuros, como a da cena final antológica da fuga do par amoroso em Blade Runner no sobrevôo dos campos verdes e fecundos de estéril solidão (VOGT, 2004).
\end{abstract}

Há os filmes espetaculares como Jornadas nas Estrelas (Star Trek, 1979) e Perdidos no espaço (Lost in Space, 1998), ícones do imaginário pop, cult movies exibidos também na TV, gravados em videocassetes, DVDs, muitos deles já disponíveis nos sites de vídeos da internet. São obras que sedimentam uma camada importante da imaginação mitológica, que funcionam para nós de maneira similar às mitologias antigas para os nossos ancestrais; têm o seu lado clichê, mas a sua elaboração se nutre dos arquétipos primordiais que vêm orientando os humanos desde a origem dos tempos.

Há, por outro lado, os clássicos, como Metropolis (1927), Fahrenheit 451 (1966), 2001: uma odisséia no espaço (1968), que forjaram uma idéia de modernidade projetada no futuro e hoje acessíveis aos pesquisadores, colecionadores e aficcionados.

A indústria do cinema não cessa de refinar as suas impressões e visibilidades sobre um tempo futuro, que em grande parte já se tornou presente no imaginário e na vida social; isto se vê em filmes como O exterminador do futuro (1984), Robocop (1987) e 
Inteligência Artificial (2001).

O cinema de ficção historicamente tem armazenado uma "memória do futuro", em que a tecnologia constitui uma espécie de "ossatura simbólica”. As telas há muito tempo nos habituaram com a idéia do futuro atravessado pela tecnologia, em que as máquinas, os andróides, os ciborgues, os clones são cópias, cúmplices e rivais dos humanos. Este tipo de filmes tem nos fornecido insights que nos levam a pensar sobre as relações entre os seres humanos e os objetos tecnológicos. O gênero de ficção - seja este visionário, crítico, conformista ou apocalíptico face à tecnologia - não deixa de instigar uma reflexão aguda sobre o enigma do mundo contemporâneo, em que o virtual se tornou atual, em que o mundo imaginário se tornou real, em que o ser humano convive com o "pós-humano".

\title{
Máquinas de visão e iluminações do pensamento
}

\begin{abstract}
A ficção científica não nos projeta para o futuro, ela nos relata estórias sobre o nosso presente e, mais importante, sobre o passado que gerou o presente. Contra-intuitivamente, a FC é um modo historiográfico, um meio de escrever simbolicamente sobre história (AMARAL, 2004, p. 4).
\end{abstract}

As luzes e sombras dos filmes de ficção, hoje, nos dão a impressão de que o mundo utópico de Júlio Verne adquiriu substância histórica e se tornou verdadeiro. Assistindo às adaptações e inspirações cinematográficas dos livros de Asimov (1981), Philip K. Dick (1983) e William Gibson (2003), percebemos como a realidade virtual (fruto da cultura digital) é prenunciada pela ficção científica (produto da cultura literária e audiovisual). Diante do mundo ficcional do cinema, hoje tão semelhante à própria realidade cotidiana, somos impelidos a refletir sobre o significado da chamada "virtualidade real" (CASTELLS, 1999), sobre o sentido desse universo paralelo, uma "outra forma de vida" que nos intriga e, ao mesmo tempo, nos deixa fascinados.

Hoje, em nossas pequenas experiências e vivências eletrônicas, assistimos aos cursos e conferências à distância, interagimos com os expositores e o público, exploramos os relevos e territorialidades do globo terrestre - num programa virtual como o Google Earth; mergulharmos no universo dos games, dos jogos e ambientes virtuais como Second Life, onde podemos mudar de personalidade, conhecer e nos comunicar com outras pessoas; também podemos vigiar os nossos lares, observar os filhos, por meio de câmeras e outros dispositivos telemáticos, pode-se até mesmo namorar e a partir dos encontros virtuais nos chats, nas salas de bate-papo. Então, sentimos uma estranha familiaridade, quando revemos as velhas fitas de ficção científica. E hoje, na era digi- 
tal, invade-nos a sensação de já termos vivenciado as experiências virtuais, sensação semelhante a uma regressão psicanalítica, que nos remete às antigas imagens do passado, quando revemos os antigos filmes futuristas. Estas películas, com olhares distintos, resgatam (e atualizam) parte de nossas verdades e ilusões perdidas, daí o seu poder de libertação e catarse.

\section{Uma nova ambiência comunicacional}

É importante saber explorar a nova ambiência midiática, tecnológica, que nos envolve; cumpre tirar proveito desta surpreendente hiperrealidade: Primeiramente porque tudo isso transformou os modos de ser-e-estar no mundo, mudou a relação dos seres humanos com o meio ambiente, e isto implica modificações nas modalidades de escolha, nas tomadas de decisão, nas formas de interagir no mundo. Depois porque mudaram os referenciais que nos orientavam no que diz respeito à nossa participação no chamado "mundo real". E, finalmente, porque mesmo tendo a consciência de que a realidade virtual, o universo paralelo, a hiperrealidade, forjados pelas tecnologias, são produtos da nossa imaginação criativa, da racionalidade humana, de nossa inteligência sensorial e cognitiva, experimentamos a sensação de que essa ambiência fantástica nos escapa e nos controla.

O universo paralelo que nos rodeia é como o enigmático "monólito" do filme 2001: uma odisséia no espaço; então, o desafio que se impõe aos contemporâneos é decifrar o sentido e atuar sobre essa "estranha realidade", impregnada de ficção e de virtualidade.

Quinhentos anos atrás o mundo se revolucionava porque a Europa havia descoberto o Novo Mundo, território estranho, diferente, misterioso, exótico, que derrubou a ordem estabelecida do Velho Mundo. Hoje, no limiar do novo milênio, o desenvolvimento tecnológico abriu-se para outro novo mundo, desta vez o mundo paralelo da virtualidade. E é neste mundo que viveremos o século 21

MARCONDES FILHO, 1997, p.12.

Uma exploração das obras de ficção pode atualizar decisivamente uma perspectiva histórica do pensamento acerca das influências da cultura tecnológica, sobre as formas de pensar, falar e agir dos humanos. Em sua longa trajetória, o cinema tem desnudado uma história dos usos (e abusos) da tecnologia, e é preciso permanentemente estar atento para as possibilidades abertas por estas criações humanas e fundamentalmente aprender a tirar partido deste fato que pode elevar a qualidade de vida simbólica, afetiva, cultural.

O mundo imaginário do cinema tem traduzido, por meio das imagens e sons, 
uma história dos meios técnicos e das mediações humanas. De maneira similar, por meio das noções e conceitos, pensadores como Heidegger, Chardin, Bachelard, Simmel, Benjamin, McLuhan, Flusser têm nos ajudado a entender uma história da relação entre os seres e os dispositivos tecnológicos.

O cinema não cessa de atualizar a filosofia e vai fundo na contemplação da sociedade midiatizada (e da cultura tecnológica), adicionando um componente audiovisual, lúdico e afetivo, e por meio de uma razão sensível, revigora a imaginação crítica, vigilante e investigativa acerca do chamado "universo paralelo".

Em nossa época de múltiplas conexões e hipertextualidades, dispomos de um acervo importante de estudos para uma contemplação das relações entre os seres humanos, as artes e as mídias, particularmente, o cinema.

Nesta direção, há livros surpreendentes como Cinema, imagem-movimento (DELEUZE, 1985) e Cinema, imagem-tempo (DELEUZE, 1990), obras fundamentais no contexto da filosofia pós-moderna e da imaginação do cinema, em que o pensador da pós-psicanálise (esquizo-análise) atualiza e revigora as suas reflexões no campo do desejo (após Freud e Lacan) e do poder (após Marx e seus epígonos). O filósofo coloca em perspectiva a relação entre os homens e os sonhos, mirando o inconsciente, as suas representações e simulacros. Para Deleuze, os simulacros gerados pela arte tecnológica do cinema irradiam uma outra lógica do sentido e são fundamentais para entendermos a forma e o sentido do imaginário do pós-humano, atravessado simultaneamente pelas "imagens ótico-sonoras", "imagens-lembrança” e "imagens sensório-motoras", que nos revelam o mundo distintamente da representação tradicional

O cinema pensa: uma introdução à filosofia através do cinema (CABRERA, 2006) é uma obra que, a partir das leituras de pensadores como Platão, Aristóteles, Kant, Heidegger e Wittgenstein, mostra como o cinema apresenta os conceitos-imagens, os conteúdos racionais, sensíveis, lançando luzes sobre a complexidade do mundo vivido, por meio de uma linguagem audiovisual em diálogo permanente com a filosofia.

Deleuze e o cinema: filosofia e teoria do cinema (Vasconcelos, 2006) é uma obra em que o autor retoma as noções-chave de Deleuze, a "imagem-movimento" e a "imagem-tempo". E, dialogando com os conceitos de imagem em Bergson (com ênfase no conceito de "duração", signo em Peirce (destacando a "tridimensionalidade" do sentido) e tempo em Kant (ressaltando o poder da "faculdade de julgar"), focaliza a narrativa cinematográfica fazendo interface com os problemas da arte, filosofia, técnica e sociedade. Carta aberta de Woody Allen para Platão (RIVERA, 2006a), um livro irônico, bem humorado, que apresenta a sala escura do cinema, como uma "caverna iluminada", como "kairós", instante, intervalo e oportunidade para exercício do pensamento e da ação. Rivera é autor de outros títulos surpreendentes como O que Sócrates diria a Woody Allen (RIVERA, 2004), em que discute questões extemporâneas como a ética, o amor, a felicidade, o acaso, a falta de vontade, o pressentimento inquietante da morte. É autor ainda de Stars War, mais poderoso do que nunca (Rivera, 2006b): um texto que - recorrendo a Platão, Aristóteles, Heidegger, Hegel e outros - explora os temas da vida, morte, acaso, 
destino, arbítrio, força, potência, mostrando como a ficção científica pode conduzir o leitor-espectador a uma rigorosa modalidade de reflexão filosófica, discurso lúcido e ação afirmativa.

Relembrando Deleuze, há livros para serem lidos como se assiste aos filmes e há filmes para ser assistidos como se lêem os livros. Nessa direção, há filmes densos, bonitos e ao mesmo tempo insólitos como Quero ser John Malkovich (Being John Malkovich, 1999), Vanilla Sky (2001), Brilho eterno de uma mente sem lembranças (Eternal Sunshine of the Spotless Mind, 2004); não são exatamente obras de ficção científica, mas o seu caráter de ficcionalidade pode orientar um debate sobre o universo paralelo forjado pela arte tecnológica do cinema.

Estes títulos constituem exemplos extraordinários pela forma como evidenciam as sensações do Ser na sociedade pós-industrial, num mundo em que os referenciais de espaço e tempo, essência e aparência, identidade e alteridade se modificaram radicalmente. São sinais evidentes de como o cinema pode instigar os nossos pensamentos acerca dos pequenos e grandes enigmas da vida; mostram visualmente as noções que têm sido caras a diferentes filósofos empenhados em discutir o problema da representação e da simulação, do pós-humano e da realidade virtual, como Jean Baudrillard (1997), mais assustado e iconoclasta, ou como Deleuze (1990), mais niilista e provocante. Oscilando entre uma mímese, uma representação fidedigna do real e um simulacro da dita realidade histórica, encontramos ficções que nos tocam fundo, no que respeita às noções de identidade e de alteridade, diferença e repetição, autenticidade e cópia da vida, dos seres, das coisas. O mundo das sci-fi abre as portas, sobretudo, para uma percepção da parte sublime e a estranheza do Ser no "admirável mundo novo" do século XXI.

A civilização que vem chegando aposta no super-homem e na super-humanidade. Teremos supercorpos geneticamente perfeitos, informaticamente equipados com sensores e próteses, superambientes isolados dos vírus e das pestes, supersociedades computadorizadas em que tudo é administrado, corrigido, perfeito. A utopia eleva o místico à estatura do factível. Superciber é a fantasia do futuro, projeto utópico e universal para o homem. Mas - como todas as ideologias - não prevê o furo, o impensável, o assalto do aleatório, do estranho, do "mal"

MARCONDES FILHO, Superciber, 1997, p. 5.

\section{Sexo, afeto e arte tecnológica}

Um exemplo radical da experiência simbiótica entre os seres e as tecnologias se verifica no campo dos afetos, das emoções e da sexualidade, em sua versão cibernética. 
Esta circunstância reaparece em toda a sua potência quando ingressamos no mundo digital dos chats, das salas de bate-papo, em que se inscrevem o amor on line, as interações, os afetos e as sexualidades virtuais. Concorre para uma elucidação destas experiências o livro Love on line, do filósofo inglês Aaron Ben-Ze'ev (2004), fruto de uma exaustiva pesquisa sobre os amores em rede. Além disso, no Brasil, encontramos as obras de Rachel Paiva (2000) e Sérgio Porto (1999), a primeira, com um olhar mais clínico, psicanalítico, contempla a experiência da sexualidade digital pelo prisma conceitual da "histeria", uma derivação evidente da obra freudiana; já o livro organizado por Sérgio Porto, filosófico, hermeneuta, é mais compreensivo e liberal, no exame dos afetos e sexualidades virtuais. Embora tais exemplos possam parecer dispersos e desfocados com relação ao tema, apontam para o mundo "surreal" que resulta da simbiose entre a mídia, cultura e tecnologia.

Desde os primórdios, o cinema tem atualizado uma percepção da vida afetiva e sexual por intermédio dos dispositivos tecnológicos. Neste filão, relembramos o ícone pop sensual dos anos 60, Barbarella (1968), em que a super-heroína espacial (Jane Fonda) se recusa a fazer o amor virtual apenas tocando as palmas das mãos dos parceiros, seduz um belo anjo cego, fazendo explodir orgasticamente uma máquina sexual. Já em Fahrenheit 451 (1966), o amor é subversivo, como, aliás, também o é na adaptação (em 1984) do livro de George Orwell, 1984 (2003) e no filme futurista Gattaca (1997). Em Blade Runner (1982) e Inteligência Artificial (A.I. - Artificial Intelligence, 2001), perambulam os andróides sexualizados, que sofrem e gozam como os humanos; em Mensagem pra você (You've got mail, 1998), o fio condutor é o amor virtual, e os encontros e desencontros amorosos se realizam através da internet; em O show de Truman (The Truman Show, 1998), não só o amor, mas a própria vida do protagonista é forjada por uma gigantesca corporação tecnomidiática; em Medo ponto com (Fear dont com, 2002), um assassino serial aterroriza as suas vítimas por meio de um site na internet.

Uma fina leitura da condição dos seres humanos nas tramas da realidade virtual do cinema, que antecipa a ambiência tecnológica do século XXI, pode ser encontrada no texto de Vieira e Coelho (2004), sintomaticamente intitulado Subjetividade virtual em nova carne e com o subtítulo "O fim do tempo, espaço e corpo orgânico no sujeito recriado", uma análise aguda dos filmes de Cronenberg:

Videodrome e eXistenZ são filmes que se alinham à já tradição crítica de uma realidade gerada pela tecnologia a partir do pós-guerra e representada por [vários] autores [...]. Particularmente em relação ao cinema, os filmes em questão realçam as transformações geradas a partir de nossa relação com a biotecnologia e a partir do discurso da mídia contemporânea. Referem- se a um apagamento de fronteiras de gênero e de suportes tecnológicos de informação, ou entre cultura de elite e cultura popular; entre o real e o imaginário e, principalmente, entre formas hegemônicas e experimentais de represen- 
tação audiovisual. Na era dos seres de proveta, cyborgs, clones, pele artificial, proteína animal aplicada em chips e da realidade virtual, o cinema de Cronenberg dramatiza uma espécie de espaço de acomodação para uma nova existência tecnológica. Através de habilidosa combinação de linguagem, iconografia e narração, o choque do novo é simultaneamente estetizado e investigado. O espectador desse jogo acaba habitando e se habituando com um mundo repleto de alterações cognitivas e figurações poéticas, que refletem suas próprias configurações sociais, tais como estão sendo construídas e modificadas pela tecnologia de engenharia genética de ponta

(Vieira e Coelho, 2004, p. 2-3).

O cinema nos habituou às estranhezas mais intimistas da nossa "modernidade líquida", em que as identidades não cessam de se multiplicar, se desmanchar, se reconstituir. As experiências de construção, desconstrução e reconstrução das identidades, no contexto das mídias e das sociedades (pos)industriais e tecnológicas, já prognosticadas por Walter Benjamin, principalmente em seus estudos sobre a obra de Baudelaire (BENJAMIN, 1989). Tais experiências têm sido revisitadas - em diferentes registros - por autores como Bauman (1998), Hall (2002), Giddens (2002), que buscam os indícios, os sinais, os espectros geradores das formas de agregação e exclusão social. Estes estudiosos nos ajudam a perceber como o cinema, iconicamente, imagetiza as identidades individuais e sociais.

Persiste um certo consenso dentre os intelectuais, "leitores imersivos" dos cult movies de ficção, quanto ao fato de termos nos tornado "estranhos a nós mesmos" (KRISTEVA, 1994), de experimentarmos as emanações de "um exotismo interior" (GUILLAUME, 1989).

Esta nova (des)ordem, tão sensível e evidente nos tempos dos realities shows, da vida digital, do amor virtual, do Ser no ciberespaço, pulsa na espessura estética e mitológica do cinema, desde as suas origens, e daí podemos tirar alguns ensinamentos.

O medo, a coragem, o horror, a compaixão imaginados visualmente e acusticamente nestes filmes nos habituaram a uma ética-estética afirmativa.

\section{Ética e estética do cinema na era do virtual}

A sétima arte, desde o período da alta modernidade industrial, constitui um lócus privilegiado para decifrarmos o sentido da natureza afetiva, psicológica e cognitiva de nossas extensões tecnológicas. Isto resplandece em obras ficcionais "já antigas" como O dia em que a terra parou (The day the earth stood still, 1941), Poltergeist, o fenômeno (Poltergeist, 1982) e O exterminador do futuro (Terminator, 1984). Aparece estética e 
filosoficamente mais elaborado em obras complexas como Quero ser John Malkovich (Being John Malkovich, 1999). No filme, os seres humanos chegam às ultimas conseqüências, em suas pulsões narcisistas e crises de identidade, entrando literalmente na cabeça do Outro, projetando-se organicamente na essência mitológica de um ídolo, no caso, o ator John Malkovich, ele próprio tornado personagem de ficção. O mesmo ocorre com a película Brilho eterno de uma mente sem lembranças (Eternal Sunshine of the Spotless Mind, 2004): psicologicamente profundo, crítico, problematizador, mostra a relação de um casal que optou por se utilizar de dispositivos tecnológicos para modificar as suas memórias afetivas e sexuais, fazendo com que cada um dos pares se esquecesse das mágoas e decepções recíprocas.

De forma mais extrema, o poder das máquinas de virtualidade, da inteligência artificial atuando sobre a vida dos humanos, mostra-se, com evidência, no espanhol Preso na escuridão (Abre los Ojos, 1997), refilmado por Cameron e interpretado por Tom Cruise (Vanilla Sky, 2001): aqui, o avanço da engenharia genética torna possível o ser humano usar a tecnologia para interferir nos processos de longevidade, prolongando o tempo de vida, forjando a própria imortalidade.

Observando as estruturas básicas das narrativas do cinema de ficção científica, encontramos os termos de uma antropológica da comunicação, em que as imagens da vida, do trabalho, da linguagem (Foucault, 1990) são projetadas numa modalidade de memória afetiva que, de longe, do passado histórico-ficcional, pode orientar os indivíduos no século XXI. Os filmes que já eram futuristas, desde as origens do cinema de ficção, podem ser vistos como simulacros fundamentais para visualizarmos e discutirmos as formas do ethos, ética, educação, habitus, consciência, os modos da percepção e dos afetos vigentes hoje, na época da cibercultura. A formação de um "ethos midiatizado" (SODRÉ, 2002), um ethos tecnológico, norteador do estilo de conduta diante de si, do outro, do meio ambiente, constitui um novo dispositivo sociotecnológico que impõe desafios para os filósofos, estetas, antropólogos e sociólogos contemporâneos.

São importantes, neste sentido, autores-leituras atentos para a potência da razão sensível e inteligência afetivo-sensorial; ver então, as obras e textos de Maffesoli (Lógica da razão sensível), Kerckhove (A pele da cultura), Di Felice (Pós Humanismo), entre outros.

E a propósito, um olhar crítico, sagaz e humorado sobre o homem dominado, que escapa do mundo controlado pelos processos midiáticos, impõe-se vigorosamente, em filmes com finais surpreendentes como O show de Truman (1998), visto por Baudrillard como hors d'oeuvre que supera - de longe - Matrix, ideologicamente e esteticamente, com trilha sonora de Philip Glass.

As novas técnicas de informação e de comunicação são mais que instrumentos, próteses, ou extensões dos nossos sentidos. Internet, ciberespaço e realidade virtual são novas maneiras de integração homem-máquina: a máquina é o novo ambiente das nossas experi- 
ências. Nesta integração que é um movimento entre seres biológicos e seres maquínicos, corpo e pensamento, matéria viva e inerte, carne e silício, nossas referências tradicionais se vêem fragilizadas e talvez só possamos compreender o que se passa recorrendo às lições de filmes como Blade Runner ou Gattaca (TUCHERMAN, 2004, p. 2).

Em se tratando do ciberespaço, existem autores importantes, no campo da comunicação e suas interfaces com os campos da arte, técnica e sociedade, aptos a nos esclarecer acerca da cultura audiovisual, para além da hegemonia do mercado global das imagens. Esboçamos algumas referências do pensamento estético e comunicacional, que tem procurado se aproximar dessa cultura emergente e em permanente estado de transformação: Jameson (1995), Hutchon (1989), Youdice (2004), Barbéro e Rey (2001), Sodré (2002), Machado (2002), Santaella (2004), entre outros, partindo de perspectivas distintas, têm contribuído para um esclarecimento acerca dessa hibridação em que se mesclam a cultura massiva, a cultura midiática e a cibercultura.

\section{Para entender as tramas do mundo virtual}

Sendo este um texto de cunho ensaístico, detemo-nos no campo da especulação, e por esse prisma uma miríade de questões se inquieta, solicitando-nos uma reflexão: Quais os suportes teóricos, metodológicos e epistemológicos para revisitarmos rigorosamente a experiência cinematográfica, quando esta se volta para uma imaginação do futuro? E, mirando o cinema, como poderíamos entender as relações ocorridas no domínio híbrido, em que se entrecruzam os seres, as mídias e as tecnologias? O cinema tem sido fidedigno na representação (e simulação) das inserções vivenciais, históricas, "reais" dos indivíduos no domínio do ciberespaço, da realidade virtual, da engenharia genética, da clonagem humana? Mendonça Filho (2004), Oliveira (2004), Oppermann (2001), Panzenhagen (2001), Quintana (2004), Rivera (2006a; 2006b) são estudiosos, críticos, estetas e cinéfilos que, a partir de diferentes lugares de fala, têm lançado novas luzes sobre essas e outras questões, que perpassam as dimensões do cinema, sociedade e cultura tecnológica.

Partimos de uma perspectiva que entende o cinema como um vetor edificante para discutirmos o enigma da condição pós-humana e a sua inserção no futuro - que já se tornou presente. Enfocarmos as vivências eletrônicas, as inscrições e contingências do Ser nos universos paralelos, virtuais, hiperrealistas nos parece instigante: este é um dos caminhos pelos quais podemos entender os traços psicológicos e sociais, as formas das identidades (e identificações) individuais, sociais, culturais contemporâneas.

Uma estratégia eficaz consiste em explorar o universo das obras de ficção, que já possuem uma história no imaginário ocidental e que não cessam de se refazer, mos- 
trando e antecipando novas virtualidades e realidades pouco compreensíveis fora do âmbito da arte e da comunicação estética. Estas experiências podem ser vislumbradas ao assistirmos aos filmes como Hackers, piratas de computador (Hackers, 1995), Johnny Mnemonic, (Johnny Mnemonic, 1995), A rede (The Net, 1995), Gattaca (1997), O homem bicentenário (The Bicentennial Man, 1999), Minority Report (2002).

Nos interstícios da arte, da linguagem e da comunicação aprendemos - com a fina ironia de Umberto Eco (2006) - a rir dos radicais, apocalípticos e integrados, dos bombeiros e incendiários. Após o estouro da cultura de massa e explosão da cultura das mídias, no alvorecer da cibercultura, um desafio se impõe ao olhar contemporâneo: mirar dialogicamente as imagens, compreendendo como a "memória do futuro", forjada pelo cinema, pode instigar uma imaginação criativa e vigilante acerca da realidade histórica e virtual contemporânea.

Buscando explorar um tema específico como este, focalizando as interfaces do cinema, a realidade ficcional, a cibercultura e o mundo virtual, encontramos o interessante livro-tese de Adriana Amaral, Visões perigosas, uma arque-genealogia do cyberpunk. Comunicação e cibercultura (2006), uma varredura profunda da temática cyber, cuja apresentação de Erick Felinto se mostra esclarecedora:

Muito mais que imaginação de um futuro possível, a narrativa de ficção científica tem se apresentado como uma ferramenta valiosa para entender o nosso presente, inevitavelmente tecnológico e possivelmente pós-humano. O livro de Adriana Amaral nos apresenta, com competência e clareza, uma análise culturalista e estética da ficção cyberpunk em suas relações com determinadas tendências da tecnocultura contemporânea. Em Visões perigosas, penetramos em territórios nebulosos, estranhos e inquietantes, mas, sem dúvida, sedutores. Talvez, de fato, já estejamos vivendo no mundo imaginado por Philip K. Dick, o Virgílio que conduz Adriana pelas ora paradisíacas e utópicas, ora dantescas e apocalípticas paisagens dos novos territórios tecnocientíficos. Mapear esse espaço cultural, com seu imaginário e suas inclinações estéticas - na música, literatura, cinema - é a tarefa árdua que se propõe a autora (FELINTO, 2006, [contracapa]).

\section{Para concluir}

A perspectiva de contemplar o cinema como um dispositivo estético e epistemológico ainda é recente em nosso trabalho; por isso mesmo, buscamos lhe dar a forma de ensaio, trabalhando com noções e conceitos que são provisórios, pois tratam da cultura em processo. A memória do futuro no cinema tem longa data, mais a sua atualização na 
era digital é recente. O importante é situar desde já que as leituras imersivas do cinema, que nos envolve inteiramente pelo viés do sensível, do inteligível e do sensorial, são formas privilegiadas de acesso ao conhecimento.

Recorremos às imagens e metáforas, igualmente importantes na elaboração científica, sempre tentando decifrar as especificidades das relações entre os seres e as máquinas, a realidade histórica e a realidade ficcional, o mundo real e o mundo virtual.

Encontramos aqui um pretexto para repensar a imaginação do futuro realizada no cinema, entendendo que este manifesta tanto as formas da ideologia, quanto da utopia, e os cineastas, como os poetas e os filósofos, são também profetas e visionários. Isto se mostra em filmes de horror kitsch, como o repelente Alien, o oitavo passageiro (Alien, 1979) e num registro oposto, o doce e quase inocente E.T. - O extra-terrestre (E.T. - The extra-terrestrial, 1982). O cinema é singular ao exercer o seu poder de criar a sensação de liberdade, dar evasão à vontade de sonhar e de despertar, ao construir magníficos paraísos artificiais, em que podemos penetrar e escapar com desenvoltura.

O instante eterno do cinema cintila triunfante nos filmes inesquecíveis de Kubrick, Riddley Scott, irmãos Wachowski e Cameron; todos estes indicam o que há de mais vivo na "cultura da virtualidade real". Para além do princípio da ficcionalidade, o cinema de ficção escancara uma enorme visibilidade das coisas amadas, sonhadas e realizadas. Numa palavra, diríamos que o cinema tem o poder extraordinário de traduzir o grande enigma humano, o mistério da luz e a vontade de transcendência.

Numa revisão atualiza deste texto, caberia incluir na presente classificação o filme Avatar (James Cameron, 2010). E particularmente, gostaríamos de anotar a modesta, sublime e incisiva leitura-interpretação da obra Avatar - O futuro do Cinema e a Ecologia das Imagens Digitais (2010), um trabalho a quatro mãos, de Erik Felinto \& Ivana Bentes (2010).

\footnotetext{
"Livros como este também pressupõem uma leitura acelerada, mas é justamente esse ciclo de respostas rápidas e não distanciadas que permite a comunicação e o diálogo sobre fenômenos que ainda estão vivos na cultura. Por isso mesmo, os ensaios de Erik Felinto - centrados nas relações entre tecnologia e imagem - e de Ivana Bentes - discutindo questões de biotecnologia e poder - podem ser lidos como provocações ao pensamento e como tentativas de tornar presente uma discussão que parecia superada pelo tempo da indústria e do consumo. Assim, como Rimbaud dizia amar as "pinturas idiotas" e extrair delas uma "alquimia do verbo" (MÜLLER, 2010).
}

A cada dia aparecem mais filmes contemplando a odisséia das imagens prenunciando e atualizando a memória do virtual no cinema. Assisti-los, descrevê-los e comentá-los correspondem a expectativas e necessidades distintas. Aqui, sob o signo de Hermes, o vidente, o mediador, caberia enunciar alguns dos pequenos sustos e maravilhas 
que seduzem e alertam o espírito dos e-leitores-cidadãos-espectadores. Para além da função crítica e interpretativa, cumpre demarcar pontos de vista e lugares de fala atentos às metamorfoses que se realizam dentro e fora da tela. E é isto um pouco que fazemos aqui, criando um pretexto para pensar a nossa condição, numa era líquida, hipermoderna, pós-metafísica, em que partilhamos nossas experiências públicas e privadas com os avatares, nossos semelhantes pós-humanos.

\section{Referências bibliográficas}

AMARAL, A. Visões perigosas: uma arque-genealogia do cyberpunk. Porto Alegre, Sulina, 2006.

AMARAL, A. Blade Runner, Total Recall e Minority Reporter: cinema distópico e cyberpunk de Philip K. Dick. Sessões do Imaginário, 11. Acessado em: 03/07/2007, disponível :http://www.pucrs.br/famecos/pos/sessoes/11/6adriana.pdf.

ASIMOV, I. O homem bicentenário. Porto Alegre, Ed.L\&PM Pocket, 1981.

BARBÉRO, M. J. e REY, G. Os exercícios do ver: hegemonia audiovisual e ficção televisiva. São Paulo, Senac, 2001.

BAUDRILLARD, J. Tela total: mitoironias da era do virtual e da imagem. Porto Alegre, Sulina, 1997.

BAUMAN, Z. O mal estar na pós-modernidade. Rio de Janeiro, Zahar, 1998.

BENJAMIN, W. Charles Baudelaire, um lírico no auge do capitalismo. São Paulo, Brasiliense, 1989.

BEN-ZE'EV, A. Love on line: emotions on the internet.Cambridge, ambridge University Press, 2004.

CABRERA, J. O cinema pensa. Rio de Janeiro, Rocco, 2006.

CASTELLS, M. A era da informação: economia, sociedade e cultura. Vol. 1: A sociedade em rede. Rio de Janeiro, Paz e Terra, 1999.

DELEUZE, G. Cinema: imagem-movimento. São Paulo, Editora Brasiliense, 1985.

DELEUZE, G. Cinema II: imagem-tempo. São Paulo, Brasiliense, 1990..

DICK, P.K. Blade Runner, o caçador de andróides. Rio deJaneiro, Francisco Alves, 1983.

ECO, U. Apocalípticos e integrados. São Paulo, Perspectiva, 2006.

FELINTO, E. In: A. AMARAL, Visões perigosas: uma arque-genealogia do cyber- 
punk. Porto Alegre, Sulina, 2006. [contracapa]

FOUCAULT, M. As palavras e as coisas. São Paulo, Martins Fontes, 1990.

GIBSON, W. Neuromancer. São Paulo, Aleph, 2003.

GIDDENS, A. Modernidade e identidade. Rio de Janeiro, Zahar, 2002.

GUILLAUME, M. La contagion des passions: Essai sur l'exotisme intérieur. Paris, Plon, 1989.

HALL, S. A identidade cultural na pós-modernidade. São Paulo, Ed. DP\&A, 2002.

KRISTEVA, J. Estrangeiros para nós mesmos. Rio de Janeiro,Rocco, 1994.

MACHADO, A. Pré-cinemas e pós-cinemas. São Paulo,Papirus, 2002.

MARCONDES FILHO, C. Superciber: a civilização místico-tecnológica do século XXI. São Paulo, Ática, 1997.

MENDONÇA FILHO, K. Andróides sonham com carneirinhos elétricos? Revista Cinemascópio, 15, 2004. Acessado em:03/07/2007, disponível em: http://cf.uol.com.br/ cinemascopio/artif.cfm?CodArtigo $=49$.

OLIVEIRA, F.R. A ficção científica e a questão da subjetividade homem-máquina. ComCiência: Revista Eletrônica de Jornalismo Científico, 59, 2004. Acessado em: 03/07/2007, disponível em: http://www.comciencia.br/reportagens/2004/10/08.shtml. 